\title{
Differential expression and selective localization of vascular permeability factor/vascular endothelial growth factor in the rat uterus during the estrous cycle
}

\author{
A R Karuri, A M Kumar and D Mukhopadhyay ${ }^{1}$ \\ Department of Biomedical Sciences, Tufts University School of Veterinary Medicine, 200 Westboro Road, North Grafton, Massachusetts 01536, USA and \\ ${ }^{1}$ Department of Pathology, Beth Israel Deaconess Medical Center and Harvard Medical School, Boston, Massachusetts 02215, USA \\ (Requests for offprints should be addressed to D Mukhopadhyay, Department of Pathology, Beth Israel Deaconess Medical Center, Brookline Avenue, Boston, \\ Massachusetts 02215, USA)
}

\begin{abstract}
This study examines the expression of the multi-functional cytokine, vascular permeability factor/vascular endothelial growth factor (VPF/VEGF) in the rat uterus during early proestrus, proestrus, estrus and diestrus. Groups of ovariectomized or hypophysectomized rats served as endocrine controls. Expression of VPF/VEGF mRNA was 2 -fold greater in uteri during proestrus and estrus than in other phases of the estrous cycle. In situ hybridization techniques indicated that VPF/VEGF mRNA expression was confined to the luminal epithelium during proestrus, but shifted to the stromal compartment during estrus. Ovariectomized, hypophysectomized or diestrus rats exhibited scattered localization of VPF/VEGF mRNA
\end{abstract}

among glandular epithelium and endometrial stromal compartments. Although VPF/VEGF mRNA was expressed throughout the estrous cycle, but in different compartments of the endometrium depending on the stage of the estrous cycle, VPF/VEGF protein expression appears to be restricted to the epithelial compartment during proestrus and estrus. Results indicate that circulating levels of gonadal steroids and LH may be associated with the differential expression of VPF/VEGF mRNA and its translation activity in the endometrium during different stages of the estrous cycle.

Journal of Endocrinology (1998) 159, 489-499

\section{Introduction}

Vascular permeability factor (VPF), also termed vascular endothelial growth factor (VEGF), is a homodimeric glycoprotein of about $45 \mathrm{kDa}$ that exhibits two important functional characteristics: potent microvascular permeability enhancing activity to macromolecules in excess of 50000 times that of histamine (Dvorak et al. 1979, Senger et al. 1983) and selective mitogenic activity for cultured endothelial cells (Leung et al. 1989, Tischer et al. 1991). Human VPF/VEGF appears to be expressed in numerous isoforms of varying polypeptide lengths (121, 165, 189 and 206 amino acids), whereas rodent and bovine isoforms are predicted to be reduced by one amino acid (Claffey et al. 1992). Although only one isoform having 121 amino acids lacks heparin binding capacity (Gitay-Goren et al. 1996), all isoforms have the ability to trigger vascular permeability (Senger et al. 1986). Synthesis of different heparin-binding molecular species of VPF/ VEGF is generated by alternative splicing (Houck et al. 1991). Longer isoforms exhibit 24 highly basic amino acids and thus are more insoluble and remain predominantly cell associated (Houck et al. 1992). Shorter forms of VPF/
$\mathrm{VEGF}_{121}$ and $\mathrm{VPF} / \mathrm{VEGF}_{165}$ are highly diffusible molecules (Houck et al. 1992). Recent studies indicate that VPF/VEGF interacts with two high affinity tyrosine kinase receptors (c-fms-like tyrosine kinase and kinase domain receptor/fetal liver kinase-1) that are selectively expressed in the vascular endothelium (Shibuya et al. 1990, Vaisman et al. 1990, Millauer et al. 1993, Quinn et al. 1993). Increased synthesis and secretion of VPF/ VEGF has been noticed in many tumors (Senger et al. 1986, Plate et al. 1992, Shweiki et al. 1992, Brown et al. 1993). VPF/VEGF induces angiogenesis in vivo, and also plays a key role during tumor vascularization (Houck et al. 1991, 1992). In addition, VPF/VEGF alters endothelial cell gene expression, inducing increased production of tissue factors and several proteases, including interstitial collagenases, urokinase-like and tissue plasminogen activator (Moscatelli \& Rifkin 1988, Montesano et al. 1996). Hypoxic conditions associated with rapid growth of cell clusters (as in folliculogenesis, corpora lutea formation or tumorigenesis) appear to trigger release of VPF/ VEGF (Koos \& Olson 1991) through c-Src activation (Mukhopadhyay et al. 1995). Other pathophysiological processes like wound healing or rheumatoid arthritis, 
which involve production of new stromal formation and angiogenesis, have also been linked to increased levels of VPF/VEGF and their receptors (Brown et al. 1992b, Fava et al. 1994, Koch et al. 1994). These observations indicate that the VPF/VEGF gene is regulated by pathophysiologi$\mathrm{cal}$ conditions that require either increased angiogenesis or increased macromolecular permeability (Fava et al. 1994).

Recent studies indicate that VPF/VEGF is a crucial molecule in pathophysiological processes like tumor growth that require well-characterized microvascular hyperpermeability, angiogenesis and stroma formation (Houck et al. 1991, 1992, Brown et al. 1992a, Fava et al. 1994, Koch et al. 1994). Several reports indicate that synthesis and secretion of VPF/VEGF are regulated by numerous factors, depending on the type of organ studied (Leung et al. 1989, Brown et al. 1992a, Shweiki et al. 1992, Cullinan-Bove \& Koos 1993, Fava et al. 1994). While hypoxia and cytokines have been shown to regulate expression of the VPF/VEGF gene under pathological conditions, endocrine factors seem to play a role in the regulation of vascular permeability and angiogenesis in reproductive organs under normal conditions (Chakraborty et al. 1995). Differential expression of VPF/ VEGF appears to be correlated well with the growth phases of blood vessels during the peri-implantation period (Chakraborty et al. 1995), and also corpora lutea formation (Phillips et al. 1990, Kamat et al. 1995). Injection of estradiol or the synthetic anti-estrogen, tamoxifen, has been shown to significantly elevate uterine VPF/VEGF mRNA expression in immature rats (Cullinan-Bove \& Koos 1993, Hyder et al. 1996). Estradiol appears to stimulate synthesis of new VPF/VEGF mRNA within 30 min after injection (Cullinan-Bove \& Koos 1993); this increase is associated with the stromal compartment below the luminal epithelium (Hyder et al. 1996). However, in adult rats exhibiting normal estrous cycles, the expression of uterine VPF/VEGF mRNA predominantly displays in the luminal epithelium during the estrogen-responsive phase, and shifts to the underlying stromal tissue during the progesterone phase (Shweiki et al. 1993). Although these studies indicate that expression of the VPF/VEGF gene is associated with changing endocrine parameters during the estrous cycle and the peri-implantation period, information on temporal associations between the expression of VPF/VEGF mRNA and VPF/VEGF protein in the endometrium under controlled endocrine status of the animal is lacking. Here, we report a striking relationship between the endocrine status of the animal and expression of VPF/VEGF mRNA in the rat endometrium and also differential localization of the message for VPF/VEGF in the luminal/glandular epithelium and stromal compartment during early proestrus, proestrus, estrus and diestrus. Finally, we also report a temporal association between VPF/VEGF mRNA and VPF/VEGF protein localization in luminal and glandular epithelial tissue but not in stromal tissue during different phases of the estrous cycle.

\section{Materials and Methods}

\section{Animals}

Adult female Sprague-Dawley rats, weighing between 180 and $200 \mathrm{~g}$, were procured from the Charles River Company (Wilmington, MA, USA). Animals were housed in an American Association for Accreditation of Laboratory Animal Care approved animal facility, and the experimental design for these studies was approved by the Institutional Animal Care and Use Committee of Tufts University in accordance with US National Institutes of Health (NIH) guidelines. Animals were housed three per cage, on a $12 \mathrm{~h}$ light:12 h darkness photoperiod, with food and water freely available.

After an acclimatization period of 7 days, the estrous cycles of all animals were monitored by daily examination of vaginal smears. Animals exhibiting two consecutive normal estrous cycles were recruited into the study. Rats were killed during estrus or diestrus $(1000-1100 \mathrm{~h})$ by decapitation. Rats entering proestrus, as determined by vaginal exfoliative cytology, were killed between 1100 and $1200 \mathrm{~h}$ (early proestrus) or between 1400 and $1800 \mathrm{~h}$ (designated proestrus). Groups of six animals were killed during each stage of the estrous cycle. Trunk blood was collected from all animals and serum was separated and stored at $-80{ }^{\circ} \mathrm{C}$ until later assay for hormones. The abdomen was opened and the entire uterus, from the tubo-uterine junction to the cervix, was isolated. Excess fat and connective tissue were trimmed off, and the left uterine horn was flash frozen in liquid nitrogen for molecular biological studies, while the right uterine horn was processed for in vivo hybridization and immunohistochemical studies.

Ovariectomized or hypophysectomized rats were obtained from Taconic Farms (New York, NY, USA) and housed as above. Animals were examined daily by vaginal smears for the presence of estrous cycles to confirm completeness of ovariectomy or hypophysectomy. Animals were killed by decapitation and examined for surgical completeness of ovariectomy or hypophysectomy. Uteri and blood samples were collected for molecular biological, immunohistochemical and in vivo hybridization studies as described subsequently.

\section{$R I A$}

Serum estradiol and progesterone were measured by RIA kits (Diagnostic Product Corp., Los Angeles, CA, USA). The detection limit of the assay for progesterone was approximately $0.02 \mathrm{ng} / \mathrm{ml}$ and the Coat-A-Count progesterone antiserum is highly specific for progesterone, with a particularly low cross reactivity to other naturally occurring steroids or therapeutic drugs that may be present in samples. Intra- and interassay coefficients of variation for the estradiol assay were 3.6 and $12.6 \%$ respectively. 
The detection limit of the estradiol assay defined as the concentration at $95 \% \mathrm{~B} / \mathrm{Bo}$ is approximately $8 \mathrm{pg} / \mathrm{ml}$ and the antiserum is highly specific for estradiol, with a relatively low cross reactivity to other naturally occurring steroids or therapeutic drugs that may be present in samples. Intra- and interassay coefficients of variation for estradiol assay were $4 \cdot 3$ and $6 \cdot 8 \%$ respectively. Serum luteinizing hormone (LH) was assayed by using an NIH rat LH RIA kit (NIDDK-anti-rLH-S-11 as anti-rat antibody; NIDDK-rLH-RP-3 (AFP-7187B) as rat LH reference preparation). Radiolabeled $\left({ }^{125} \mathrm{I}\right) \mathrm{LH}$ was purchased from Covance Laboratories Inc. (Vienna, VA, USA). Mean intra- and interassay coefficients of variation were 8.6 and $14 \cdot 8 \%$ respectively. The sensitivity of the assay was $0 \cdot 2 \mathrm{pg} /$ tube. The assay was linear at 4-128 ng/tube for LH. The LH RIA procedure has been previously described (Kumar \& Chen 1983, Kumar \& Simpkins 1983).

\section{Northern blot analysis}

Total uterine RNA was prepared by the method of Chirgwin et al. (1979). Briefly, uteri were homogenized and RNA isolated by the single step acid phenol extraction method. Samples of total RNA $(20 \mathrm{mg})$ were separated on a formaldehyde-agarose gel, transferred to GeneScreen (DuPont, Boston, MA, USA) membrane using $10 \times$ SSC, and probed with random primer ${ }^{32} \mathrm{P}-$ labeled $\mathrm{cDNAs}$ containing either $980 \mathrm{bp}$ mouse VPF/VEGF sequence common for all four known isoforms (which also recognizes rat VPF/VEGF; a generous gift of Dr Kevin Claffey, Dept of Pathology, Beth Israel Deaconess Medical Center, Boston, MA, USA), or glyceraldehyde-3-phosphate dehydrogenase $(\mathrm{GAPDH})$ and in a solution containing $0.5 \mathrm{M}$ sodium phosphate ( $\mathrm{pH} 7 \cdot 2$ ), 7\% SDS, 1\% BSA, $1 \mathrm{mM}$ EDTA and sonicated herring sperm DNA $(50 \mu \mathrm{g} / \mathrm{ml})$ at $68^{\circ} \mathrm{C}$. Blots were washed three times with a solution containing $40 \mathrm{mM}$ sodium phosphate ( $\mathrm{pH} 7 \cdot 2$ ), $0 \cdot 5 \%$ SDS, $0.5 \%$ BSA, $1 \mathrm{mM}$ EDTA at $68^{\circ} \mathrm{C}$ and then exposed to Kodak X-OMAT film. Six sets of Northern analyses were performed taking six rats from each group. Bands were quantified by densitometric analysis.

\section{Western blot analysis}

Supernatants of tissue homogenates were subjected to SDS-PAGE and immunoblotting. Western blot analysis of VPF/VEGF was performed by using the IgG fraction of rabbit polyclonal antibodies raised to a synthetic peptide corresponding to residues 1-20 of the amino terminus (Santa Cruz Biotechnology Inc., CA, USA). Antibodyreactive bands were detected by enzyme-linked chemiluminescence (Amersham, Arlington Heights, IL, USA) and quantified by laser densitometry. Six sets of Western blot analyses were performed taking six rats from each group.
In situ hybridization (ISH)

ISH was performed on $4 \mu \mathrm{m}$-thick sections of formalinfixed, paraffin-embedded uterine tissues. For comparison of expression of VPF/VEGF mRNA during different stages of the estrous cycle, six individual uterine sections randomly selected from animals in each stage of the cycle were processed. Details of the ISH procedure have been previously described (Ffrench-Constant et al. 1989). Briefly, slides were passed through graded alcohols; $0 \cdot 2 \mathrm{M}$ $\mathrm{HCl}$; Tris/EDTA with $3 \mathrm{mg} / \mathrm{ml}$ proteinase $\mathrm{K}$; $0 \cdot 2 \%$ glycine; 4\% paraformaldehyde in PBS $\mathrm{pH} 7 \cdot 4 ; 0 \cdot 1 \mathrm{M}$ triethanolamine containing $1 / 200(\mathrm{v} / \mathrm{v})$ acetic anhydride; and $2 \times$ SSC. Slides were hybridized overnight at $50{ }^{\circ} \mathrm{C}$ with ${ }^{35} \mathrm{~S}$-labeled riboprobes in the following mixture: $0.3 \mathrm{M} \mathrm{NaCl}, 0 \cdot 01 \mathrm{M}$ Tris pH 7.6, $5 \mathrm{mM}$ EDTA, 50\% formamide, $10 \%$ dextran sulfate, $0 \cdot 1 \mathrm{mg} / \mathrm{ml}$ yeast tRNA and $0.01 \mathrm{M}$ dithiothreitol. Post-hybridization washes included $2 \times \mathrm{SSC} / 50 \%$ formamide $/ 10 \mathrm{mM}$ dithiothreitol at $50{ }^{\circ} \mathrm{C} ; 4 \times \mathrm{SSC} / 10 \mathrm{mM}$ Tris $/ 1 \mathrm{mM}$ EDTA with $20 \mathrm{mg} / \mathrm{ml}$ ribonuclease at $37^{\circ} \mathrm{C}$; and $2 \times \mathrm{SSC} / 50 \%$ formamide/ $10 \mathrm{mM}$ dithiothreitol at $65^{\circ} \mathrm{C}$ and $2 \times$ SSC. Slides were then dehydrated through graded alcohols containing $0 \cdot 3 \mathrm{M}$ ammonium acetate, dried, coated with Kodak NTB 2 emulsion and stored in the dark at $4{ }^{\circ} \mathrm{C}$ for 2 weeks. The emulsion was developed with Kodak D19 developer and the slides were lightly counter stained with hematoxylin. Antisense single-stranded ${ }^{35}$ S-labeled VPF/VEGF RNA probe and its sense control were designed by Brygida Berse, and have been described previously (Ffrench-Constant et al. 1989, Brown et al. 1992a). The antisense probe hybridizes specifically with a region of VPF/VEGF mRNA common to all known VPF/VEGF splicing variants. Negative controls consisted of hybridizing consecutive serial sections from selected uterine horns to the sense cRNA probe.

Autoradiographs of the uterine sections were visualized under darkfield illumination with a Zeiss binocular microscope (New York, NY, USA) fitted with a COHU solid state TV camera (San Diego, CA, USA). ISH signals from different stages of the cycle were quantified by a computer-assisted image analysis system. Images were captured with a Data Transmission Quick Capture frame grabber board (Marlboro, MA, USA) and analyzed with a Macintosh computer. Briefly, these analyses entailed digitizing images for each tissue section, locating the objects in each frame that represented isolated or clustered cells, and quantifying the content of cell-associated hybridized probes based on pixel intensity (Marchand et al. 1993). Ten regions on each individual slide were randomly picked for silver grain count. On each slide intensity levels from designated regions were converted to grains per square micron.

\section{Immunohistochemistry}

Uterine tissue was placed in $29 \mathrm{mM}$ beta mercaptoethanol $(\beta-\mathrm{ME})$ in $\mathrm{PBS} \mathrm{pH} 7 \cdot 6$ at room temperature for $15 \mathrm{~min}$, 
Table 1 Hormone levels in various groups of animals. Each value is the mean \pm S.E.M. of determinations from six rats

\begin{tabular}{|c|c|c|c|}
\hline & $\begin{array}{l}\text { Estradiol } \\
(\mathrm{pg} / \mathrm{ml})\end{array}$ & $\begin{array}{l}\text { Progesterone } \\
(\mathrm{ng} / \mathrm{ml})\end{array}$ & $\begin{array}{l}\text { LH } \\
(\mathrm{ng} / \mathrm{ml})\end{array}$ \\
\hline \multicolumn{4}{|l|}{ Group } \\
\hline Early proestrus & $6 \cdot 57 \pm 2 \cdot 30^{\mathrm{a}}$ & $16 \cdot 78 \pm 1 \cdot 80^{\mathrm{a}}$ & $0.46 \pm 0.04^{\mathrm{a}}$ \\
\hline Proestrus & $33 \cdot 00 \pm 6 \cdot 29^{b}$ & $4 \cdot 12 \pm 1 \cdot 52^{b}$ & $14 \cdot 70 \pm 11 \cdot 10^{\mathrm{b}}$ \\
\hline Estrus & $25 \cdot 24 \pm 12 \cdot 24^{\mathrm{b}, \mathrm{c}}$ & $6 \cdot 83 \pm 1 \cdot 69^{b}$ & $0 \cdot 58 \pm 0 \cdot 10^{\mathrm{a}}$ \\
\hline Diestrus & $3 \cdot 46 \pm 2 \cdot 15^{\mathrm{a}}$ & $29 \cdot 92 \pm 2 \cdot 14^{\mathrm{a}, \mathrm{b}, \mathrm{c}, \mathrm{d}}$ & $0.41 \pm 0.03^{a}$ \\
\hline Hypophysectomy & ND & $1 \cdot 33 \pm 0 \cdot 13^{d}$ & ND \\
\hline Ovariectomy & ND & $1 \cdot 27 \pm 0 \cdot 33^{d}$ & $7 \cdot 36 \pm 1 \cdot 13^{b, c}$ \\
\hline
\end{tabular}

$\mathrm{ND}=$ not detected. For each hormone, groups with different superscript letters are significantly different from others (ANOVA with post-hoc Bonferroni test, $P<0 \cdot 05$ ).

then transferred into $3 \cdot 7 \%$ formaldehyde, $29 \mathrm{mM} \beta-\mathrm{ME}$ in PBS for $4 \mathrm{~h}$. Tissue was subsequently washed several times in cold PBS, passed through graded alcohols and xylene and embedded in paraffin $\left(55^{\circ} \mathrm{C}\right.$ melting point). Transverse sections ( $5 \mu \mathrm{m}$ thick) of uteri were mounted on slides. For comparison of immunoexpression of VPF/ VEGF during different stages of the estrous cycle, six individual uterine section slides randomly selected from animals in each stage of the cycle were processed. Selected mounted sections were deparaffinized in xylene and rehydrated. Mounted sections were then rinsed in distilled water followed by PBS. Sections were treated sequentially with pre-warmed trypsin for $20 \mathrm{~min}, 0 \cdot 3 \%$ hydrogen peroxide for $10 \mathrm{~min}$ (to block endogenous peroxidases), and $10 \%$ goat serum for $45 \mathrm{~min}$ at $37^{\circ} \mathrm{C}$. Immunolocalization of VPF/VEGF was accomplished with $\operatorname{IgG}$ fractions of rabbit polyclonal antibodies raised to a synthetic peptide corresponding to residues 1-20 of the amino terminus (Santa Cruz Biotechnology), and according to published methods (Charnock-Jones et al. 1993). Negative controls consisted of substituting pre-immune serum for the primary antibody in the immunohistochemical protocol. Tissue sections were incubated with VPF/VEGF antibody (or pre-immune serum) diluted 1:300 in blocking buffer $(10 \mathrm{ml}$ Tris buffer, $29 \mathrm{mg}$ L-lysine and $250 \mathrm{mg}$ $\mathrm{NaCl}$ ) overnight at $4{ }^{\circ} \mathrm{C}$. After washing with PBS, sections were incubated with biotinylated anti-rabbit $\operatorname{IgG}(1: 200)$ for $45 \mathrm{~min}$, rinsed with PBS and incubated with streptavidin-horseradish peroxidase (1:200 in PBS) for $15 \mathrm{~min}$. Slides were washed extensively with PBS and rinsed with $0 \cdot 5 \%$ Triton X-100 for $30 \mathrm{~s}$. Bound peroxidase was visualized using $3^{\prime}, 3^{\prime}$-diaminobenzidine $(0.5 \mathrm{mg} / \mathrm{ml})$ in PBS containing $0 \cdot 1 \%$ hydrogen peroxide as the chromogen. After immunostaining, a few tissue sections were counter stained briefly with Harris' hematoxylin.

\section{Statistical analysis}

Serum hormone levels were compared across different groups of animals by one-way ANOVA followed by a post-hoc Bonferroni test with a minimum $P<0.05$ as significant. Densitometric data from Northern and Western blots were analyzed by one-way ANOVA followed by Duncan's multiple range test. with a minimum $P<0.05$ considered significant. For in vivo hybridization techniques, grain densities per square micron at each stage of the estrous cycle were compared by one-way ANOVA followed by post-hoc Duncan's multiple range test with $P<0 \cdot 05$ considered statistically significant.

\section{Results}

\section{Serum hormone levels}

Serum levels of estradiol, progesterone and $\mathrm{LH}$ are given in Table 1. Serum LH and estradiol concentrations were greater on day of proestrus than the other stages of the estrous cycle. But progesterone levels were higher during the diestrous phase than the other stages of the cycle. Serum estradiol was barely detectable in hypophysectomized and ovariectomized rats. LH was also not detected in hypophysectomized rats.

\section{$V P F / V E G F$ mRNA}

Northern blot analysis was performed on uterine RNA samples collected during different stages of the estrous cycle. After correcting for loading (using GAPDH cDNA as a control probe), the expression of VPF/VEGF mRNA was calculated using ovariectomized samples as a control. Figure 1 shows an approximately 2 -fold increase $(P<0 \cdot 05)$ in VPF/VEGF mRNA levels during proestrus and estrus compared with early proestrus/diestrus.

\section{ISH}

During diestrus, the highest levels of VPF/VEGF expression are seen in uterine glandular epithelia and subepithelial stromal compartments, with fewer silver grains on the luminal epithelium (Fig. 2C and D). During 
A

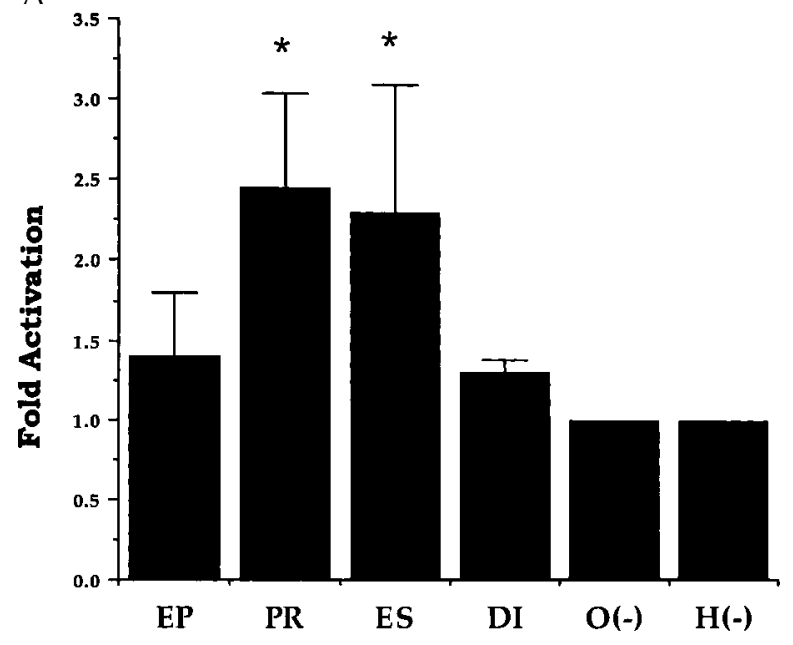

B

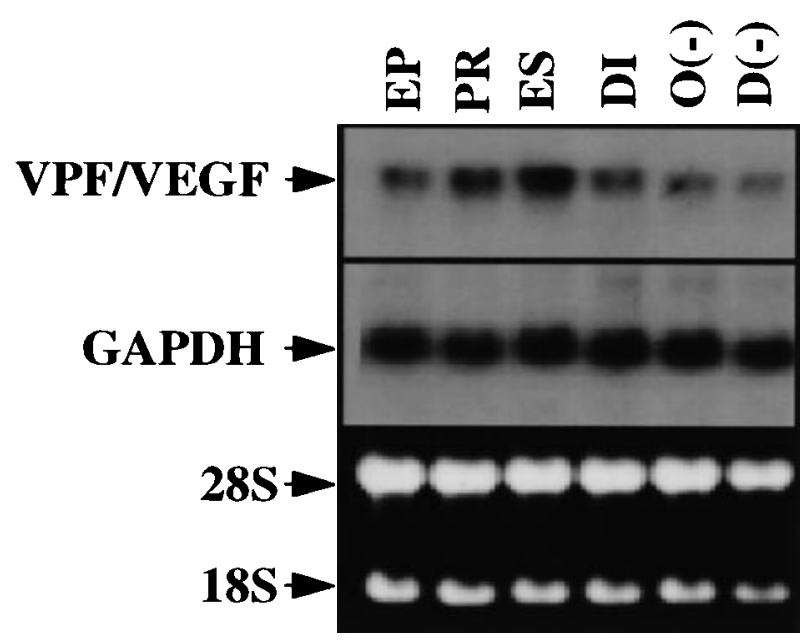

Figure 1 (A) Quantitative changes in VPF/VEGF mRNA levels of rat uteri during early proestrus (EP), proestrus (PR), estrus (ES) and diestrus (DI). Ordinate shows fold activation in mRNA, normalized to the VPF/VEGF mRNA levels in ovariectomized $(\mathrm{O}(-))$ or hypophysectomized $(\mathrm{H}(-))$ rats. (B) Quantitative representation of uterine VPF/VEGF mRNA levels during EP, PR, ES and DI, and in $\mathrm{O}(-)$ or $\mathrm{H}(-)$ rats. The filter was rehybridized with the housekeeping enzyme GAPDH to verify equal loading.

proestrus, expression of VPF/VEGF mRNA was detected primarily in luminal epithelial cells (Fig. 2E and F). Image analysis of the silver grain count reflected a significant $(P<0.0001)$ increase in mRNA content of the luminal epithelium during proestrus (Fig. 3A). The glandular epithelium also contained VPF/VEGF mRNA, but at a lower level as reflected by the number of silver grains in this area (Fig. 3B; glandular area not shown in Fig. 2E and $\mathrm{F}$ ). The stromal compartment during proestrus did not exhibit silver grains, indicating a lack of mRNA expression in this area. As animals entered estrus, the stromal compartment immediately below the luminal epithelium exhibited a high density of silver grains, with few grains in the surface epithelium (Fig. 2G and H). The glandular epithelium contained few silver grains (Fig. 3B). During early proestrus, the density of silver grains was highest in the glandular epithelial area (Fig. 3B), followed by the stromal compartment (Fig. 3A and B). However, distribution of silver grains in the stromal compartment appeared to be more scattered than during the estrus phase. Grain counts/micron of tissue section, as depicted in Fig. 3B, indicates the highest density of silver grains in the glandular epithelial area during diestrus and early proestrus, and the lowest density during estrus. VPF/ VEGF mRNA levels did not vary significantly within the luminal epithelium during estrus-diestrus. However, a significant increase in mRNA levels was noticed in the glandular epithelium during diestrus (Fig. 3A and B). The number of grains within the glandular area during diestrus and proestrus was significantly different from those during estrus $(P<0 \cdot 01)$. Control sections hybridized with a sense probe did not indicate the presence of VPF/VEGF mRNA (Fig. 2A and B). Uterine sections from ovariectomized or hypophysectomized rats exhibited a diffuse pattern of silver grains encompassing epithelial and stromal compartments. The intensity of silver grain distribution in the stroma appeared to be similar to that of diestrus rats.

\section{Western blot analysis}

VPF/VEGF protein in the uterus was detectable during early proestrus and proestrus, and increased to a maximum during the estrus phase (Fig. 4). VPF/VEGF protein was not detectable during diestrus, as well as in ovariectomized or hypophysectomized animals (Fig. 4).

\section{Immunohistochemical staining}

Immunoreactive VPF/VEGF protein was detected mainly in the luminal epithelium and partly in the glandular epithelium during different phases of the estrous cycle (Fig. 5B, D and F). No staining was detected in the stroma or myometrium. Luminal epithelial staining was lighter during early proestrus and proestrus (Fig. 5B and D), compared with estrus (Fig. 5E). During the later part of estrus, luminal epithelial staining intensity gradually decreased (Fig. 5F). During diestrus, staining for VPF/ VEGF protein was not detected in any part of the uterine endometrium. There was no detected expression of immunoreactive VPF/VEGF in the uteri of ovariectomized or hypophysectomized rats (Fig. 5G and $\mathrm{H}$ ). 

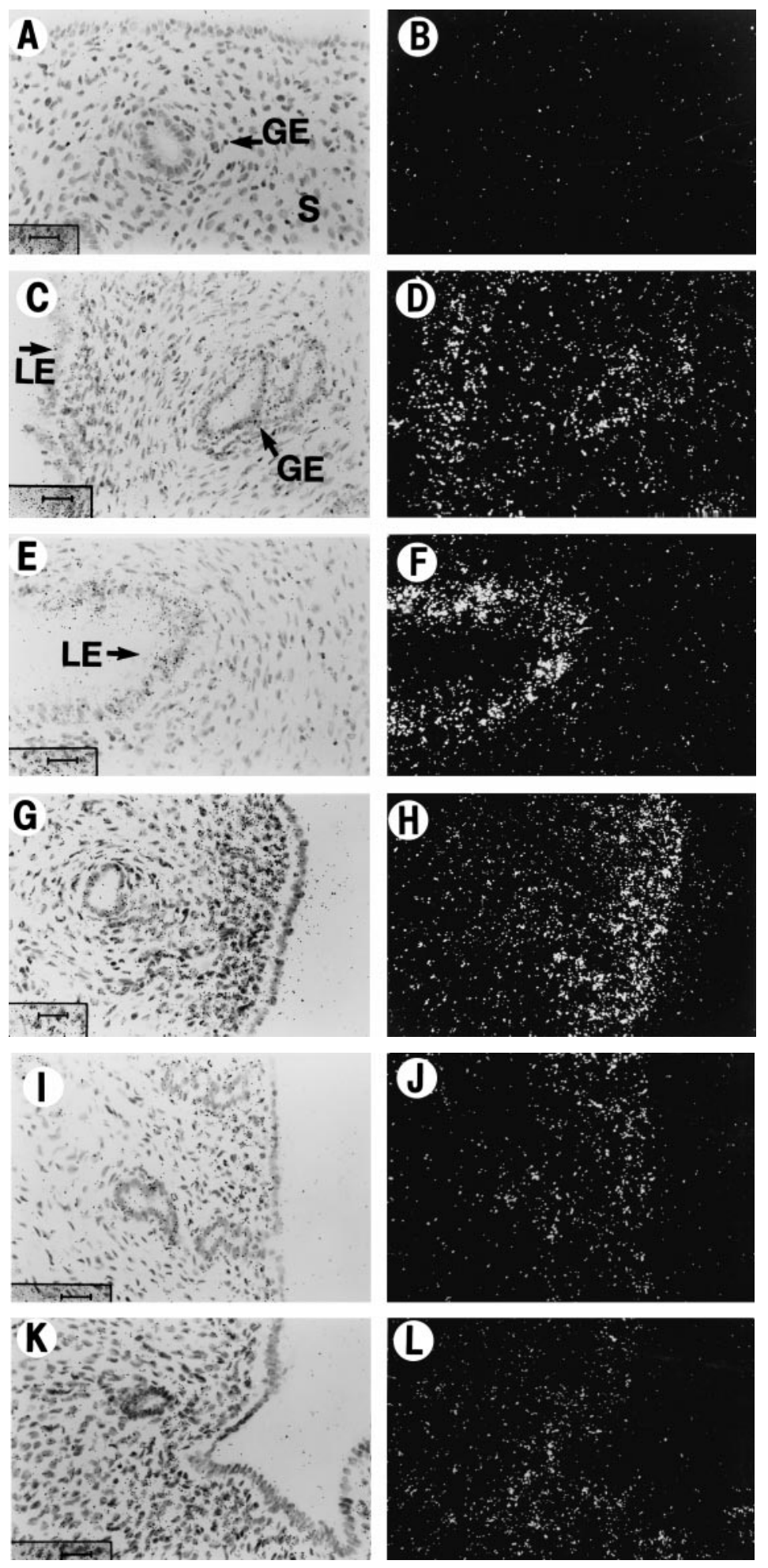

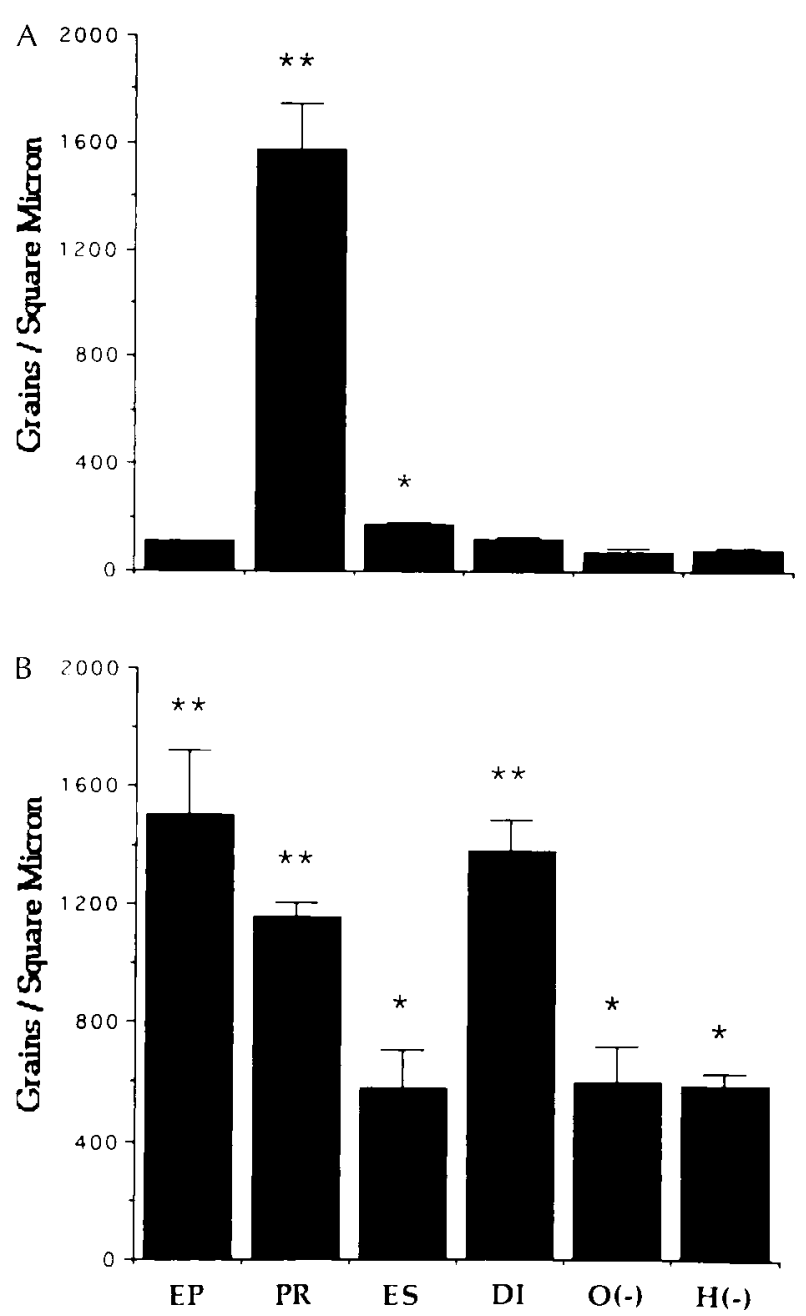

Figure 3 Density of silver grains (representing concentration of VPF/VEGF mRNA) in different compartments of rat uteri during different stages of the estrous cycle compared with ovariectomized or hypophysectomized uteri. (A) Grains/square micron of luminal epithelial area. (B) Grains/square micron of glandular epithelial area. Bars represent means \pm S.E.M. Bars with different numbers of asterisks are significantly different from others $(P<0 \cdot 01)$.

\section{Discussion}

We demonstrate in this report a variation in the level of $\mathrm{VPF} / \mathrm{VEGF}$ mRNA transcripts in rat uterine tissue during different stages of the estrous cycle. An approximately 2 -fold increase in mRNA content during proestrus

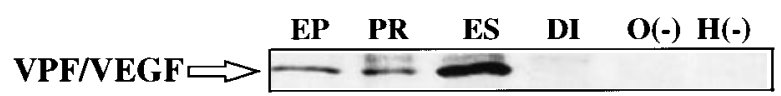

Blot: VPF/VEGF

Figure 4 Western blot analysis of VPF/VEGF protein in rat uteri during different stages of the estrous cycle and in ovariectomized or hypophysectomized uteri. Note significant level of expression during estrus, and lack of expression in diestrus, $\mathrm{O}(-)$ or $\mathrm{H}(-)$ rat uteri.

indicates a positive correlation with high serum levels of endogenous estradiol. These observations are in agreement with a previous report (Hyder et al. 1996). Predictably, high serum estradiol levels were associated with high serum LH levels during proestrus. The VPF/VEGF mRNA content remained high during estrus (Fig. 1), which was associated with relatively high levels of estradiol and decreasing levels of $\mathrm{LH}$. These results indicate either: (i) a sustained action of estradiol on VPF/VEGF gene expression resulting in increased synthesis of specific mRNA; (ii) increased mRNA stability during estrus; or (iii) stimulation of VPF/VEGF mRNA synthesis by other endocrine factors (such as progesterone). For example, progesterone alone has been shown to stimulate expression of the VPF/VEGF message (Cullinan-Bove \& Koos 1993). It is likely that a combination of the above mentioned factors is involved in maintaining a relatively high level of VPF/VEGF mRNA in the uterus. Estradiol levels in our study remained well above basal levels during estrus, providing a stimulus for VPF/VEGF gene expression, either alone or in concert with increasing levels of progesterone during estrus. In the absence of new synthesis of VPF/VEGF mRNA during estrus, a reduction in its breakdown may also result in sustained high levels of the message. It is not known whether a combination of estrogen and progesterone play a role in increasing the stability of VPF/VEGF mRNA, although there are reports of decreased mRNA degradation by the action of estrogen alone (Weisz \& Bresciani 1988). Estrogen is also thought to exert its action on estrogen-responsive elements resulting in an increase in transcriptional activity (Curtis \& Korach 1991). The issue of VPF/VEGF mRNA stability during various phases of the estrous cycle merits further investigation.

ISH techniques indicate that VPF/VEGF transcripts are localized within the endometrium. Interestingly, localization of mRNA remained mainly within the luminal

Figure 2 Light and dark field photomicrographic views of the distribution of VPF/VEGF mRNA in the uteri of rats during different phases of the estrous cycle or from ovariectomized or hypophysectomized rats. (A and B) Representative control sections (uteri during estrus probed with a sense probe). (C and D) Diestrous uterus; note VPF/VEGF mRNA localization in the stromal and glandular compartment. (E and F) Proestrous uterus; note the VPF/VEGF mRNA localization in the luminal epithelial compartment. (G and $\mathrm{H})$ Estrous uterus; note the predominance of VPF/VEGF mRNA localization in the sub-epithelial stromal compartment. (I and J) Ovariectomized uterus. (K and L) Hypophysectomized uterus. Note the scattered distribution of VPF/VEGF mRNA among glandular and stromal compartments in ovariectomized and hypophysectomized uteri. Scale bar=25 $\mu \mathrm{m}$. S, stroma; GE, glandular epithelia; LE, luminal epithelia. 

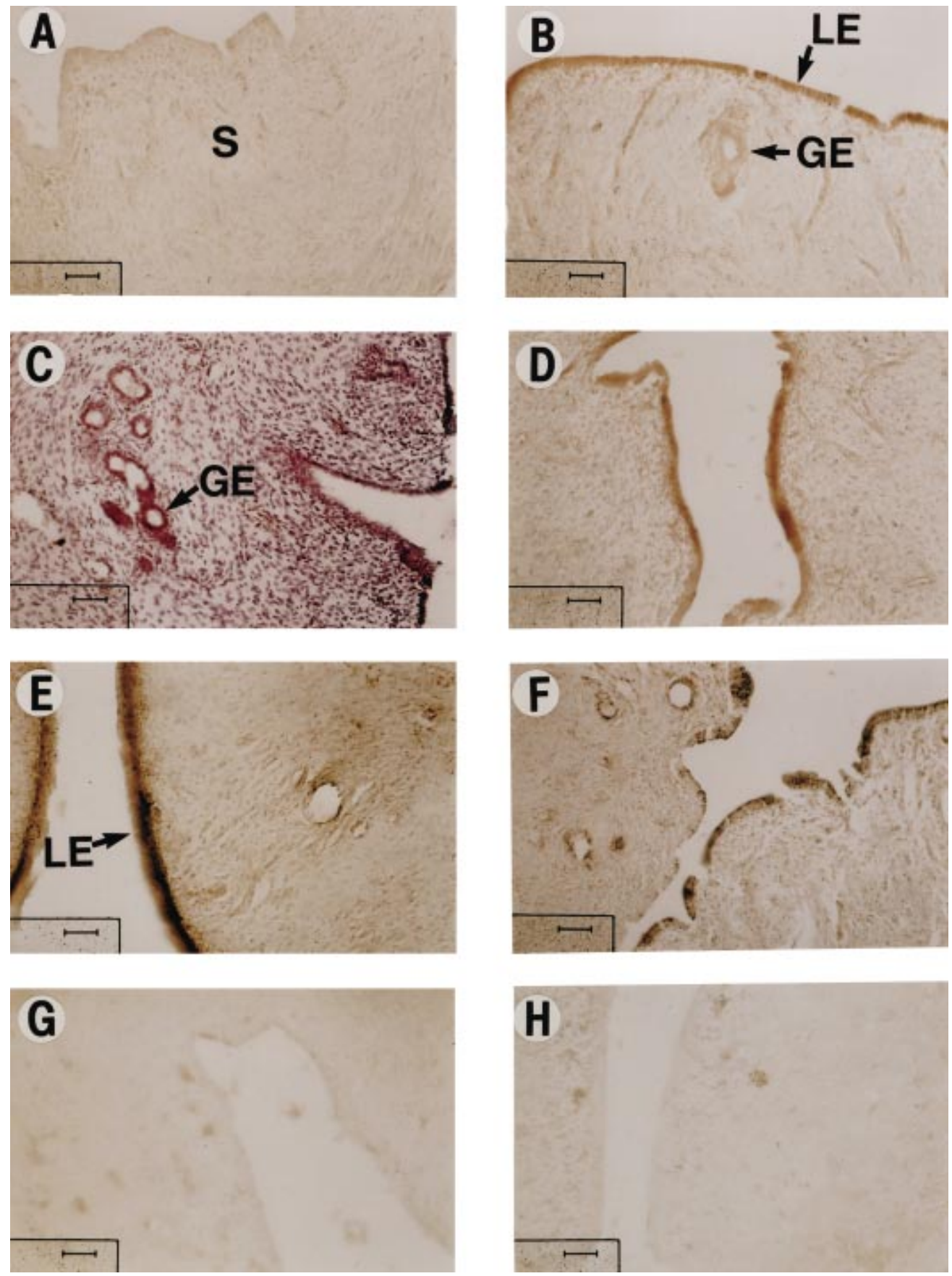

Figure 5 Representative photomicrographs showing the distribution of VPF/VEGF protein in the uteri of rats during various stages of the estrous cycle. (A) Negative control of the uterus during estrus (primary antibody substituted by pre-immune serum); S, stroma. (B) Uterus during proestrous, showing luminal epithelial (LE) and light glandular epithelial (GE) staining. (C) Proestrus uterus with VPF/VEGF staining in luminal and glandular epithelia, counter stained with hematoxylin. (D) Early estrous uterus; note the staining intensity is similar to that in the proestrous rat uterus. (E) Estrous uterus. Note the high intensity of staining for VPF/VEGF protein. (F) Section from uterus in transition from late estrus to early diestrus. Note the discontinuous VPF/VEGF protein localization in the luminal epithelium. ( $\mathrm{G}$ and $\mathrm{H}$ ) Sections from ovariectomized or hypophysectomized uteri, showing lack of staining for VPF/VEGF protein. The diestrous uterus (not shown) appeared similar to those in panels $\mathrm{G}$ and $\mathrm{H}$. Scale bar $=50 \mu \mathrm{m}$. 
epithelial area, and partly in the glandular epithelial area during proestrus, whereas in the estrus phase it was predominantly in the sub-epithelial stromal compartment. During diestrus, mRNA signals were scattered in the stromal compartment and in the glandular epithelial area (Figs 2 and 3). These results indicate that estradiol alone, or in combination with LH, may specifically activate VPF/ VEGF gene expression in the luminal epithelium while the progesterone phase is involved with activation of VPF/VEGF gene expression in the glandular epithelium and stromal compartment. In addition, we also showed that the expression of the VPF/VEGF protein itself exhibits a significant temporal trend with regard to content and localization within the uterus during various phases of the estrous cycle. Although the highest concentration of VPF/VEGF mRNA was found in the luminal epithelium during proestrus (Fig. 2), immunohistochemical localization indicated that the highest levels of this protein occurred during estrus (Fig. 5). These results may indicate several possibilities: (i) translational events associated with VPF/VEGF mRNA may occur selectively only during early proestrous/proestrous and estrous phases, resulting in significant elevations of VPF/VEGF proteins during these stages - during diestrus the message for VPF/VEGF is present within components of the endometrium, but may not be processed further; or (ii) post-translational processing events associated with VPF/VEGF protein may occur only during early proestrous/proestrous and estrous phases of the estrous cycle - it has been shown for example that VEGF factor C undergoes extensive step-wise posttranslational proteolytic processing which is required for its biological function (Joukov et al. 1997); or (iii) there may be a reduction in the rate of secretion of VPF/VEGF protein in estrus and late estrus, compared with proestrus, so that it accumulates to detectable levels. Secretion of VPF/VEGF may then increase again in late estrus/diestrus, without replacement synthesis (as indicated by low levels of VPF/VEGF mRNA in late estrus/diestrus), and this results in the return to low levels of the protein during these phases of the cycle. Detectable amounts of VPF/VEGF during early proestrus (Fig. 4) during a period when the message levels were not significantly elevated (Fig. 1) may reflect relative sensitivities of Western blot and Northern blot procedures. It is likely that subtle differences in message levels among different experimental groups of animals are not detected by Northern blot procedures.

Based upon our results, we suggest the following: early endocrine-mediated events associated with proestrus and estrus (when estrogen and LH levels are high) may initiate synthesis of the mRNA for VPF/VEGF. Translational and post-translational events associated with VPF/VEGF continue during the time period when estrogen levels are declining and the animal is entering the progestational period. Only the epithelial components of the endometrium appear capable of synthesizing the VPF/VEGF protein during the period when circulating estrogen levels are high (proestrus and transition into estrus). The stromal compartment, although exhibiting a mechanism that is endocrine sensitive with regard to synthesis of VPF/VEGF mRNA (our in vivo hybridization and Northern blot results as well as observations by Shweiki et al. 1993), nevertheless appears incapable of synthesizing the protein during the diestrous phase of the cycle. It may be possible that VPF/VEGF protein is rapidly secreted by these VPF/VEGF mRNA cells and then dispersed; there might be insufficient local accumulation for immunodetection. It is well known that the stroma contains the highest density of blood vessels, and exhibits characteristic edema during estrus. It has also been shown that the stromal compartment immediately in contact with the surface epithelium is the main site of neovascular growth in the rodent uterus (Harper 1988). Although speculative, the VPF/VEGF protein synthesized by the luminal and glandular epithelium may play a significant role in inducing neovascular growth and vascular permeability during the luteal phase by diffusing into the underlying stromal compartment. This type of selective VPF/VEGF expression only in the epithelial compartment during the short luteal phase of the rodent may differ from the longer progesterone phase observed during pregnancy. Speculative extrapolations from published work on rat uterine VPF/VEGF mRNA expression during early implantation (Chakraborty et al. 1995) would indicate that a shift occurs in the synthesis of VPF/VEGF from the epithelial to the stromal compartment during pregnancy.

We also report expression of low levels of VPF/VEGF mRNA in the stromal compartment and in the glandular epithelium of ovariectomized or hypophysectomized rats (Fig. 2). The levels of VPF/VEGF mRNA in these animals appeared to be similar to those observed during diestrus in intact rats. Although, unlike diestrus animals, ovariectomized rats exhibited sustained high levels of $\mathrm{LH}$ but low levels of estradiol, the exact role of LH in regulating the expression of VPF/VEGF mRNA in the endometrium remains to be resolved. It is likely basal levels of estradiol in ovariectomized animals meet the threshold stimulus to sustain a low level expression of VPF/VEGF mRNA in the endometrium. Equally likely, low level expression of VPF/VEGF expression in ovariectomized animals indicates that a basal level of VPF/VEGF mRNA expression within the stromal and glandular compartment may be an intrinsic property of the rat uterus, independent of hormonal influence. Further, under quiescent endocrine conditions, stromal and glandular VPF/VEGF mRNA may remain untranslated into a protein product unless the animal becomes pregnant. It is likely that factors secreted by the embryo itself, or in combination with an altered endocrine profile due to pregnancy, may trigger translational events associated with uterine VPF/VEGF mRNA. These are important issues for successful implantation of the embryo, and we are at present examining the role played by the embryo in 
initiating implantation-associated VPF/VEGF expression in the pig model.

\section{Acknowledgements}

This study was supported in part by a United States Department of Agriculture small grant program. We wish to thank Professor Larry Engelking, Departments of Biomedical Sciences and Physiology, for critical reading of the document. This work was partly supported under terms of a contract from the National Foundation for Cancer Research. We also thank Lawrence F Brown for carrying out in situ experiments. We would like to thank Harold Dvorak for his encouragement in this work. A M K and D M contributed equally to this work.

\section{References}

Brown LF, Berse B, Tognazzi K, Manseau EJ, Van De Water L, Senger DR, Dvorak HF \& Rosen S 1992a Vascular permeability factor mRNA and protein expression in human kidney. Kidney International 42 1457-1461.

Brown LF, Yeo KT, Berse B, Yeo TK, Senger DR, Dvorak HF \& Van De Water L $1992 b$ Expression of vascular permeability factor (vascular endothelial growth factor) by epidermal keratinocytes during wound healing. Journal of Experimental Medicine $\mathbf{1 7 6}$ 1375-1379.

Brown LF, Berse B, Jackman RW, Tognazzi K, Manseau EJ, Senger DR \& Dvorak HF 1993 Expression of vascular permeability factor (vascular endothelial growth factor) and its receptors in adenocarcinomas of the gastrointestinal tract. Cancer Research $\mathbf{5 3}$ 4727-4735.

Chakraborty I, Das SK \& Dey SK 1995 Differential expression of vascular endothelial growth factor and its receptor mRNA in the mouse uterus around the time of implantation. Journal of Endocrinology 147 339-352.

Charnock-Jones DS, Sharkey AM, Rajput-Williams J, Burch D, Schofield JP, Fountain SA, Boocock CA \& Smith SK 1993 Identification and localization of alternately spliced mRNAs for vascular endothelial growth factor in human uterus and estrogen regulation in endometrial carcinoma cell lines. Biology of Reproduction 48 1120-1128.

Chirgwin JM, Przybyla AE, MacDonald RJ \& Rutter WJ 1979 Isolation of biologically active ribonucleic acid from sources enriched in ribonuclease. Biochemistry 18 5294-5299.

Claffey KP, Wilkison WO \& Spiegelman BM 1992 Vascular endothelial growth factor: Regulation by cell differentiation and activated second messenger pathways. Journal of Biological Chemistry 267 16317-16322.

Cullinan-Bove K \& Koos RD 1993 Vascular endothelial growth factor/vascular permeability factor expression in the rat uterus: rapid stimulation by estrogen correlates with estrogen-induced increases in uterine capillary permeability and growth. Endocrinology 133 829-837.

Curtis SW \& Korach KS 1991 Uterine estrogen receptor-DNA complexes: effects of different ERE sequences, ligands, and receptor forms. Molecular Endocrinology 5 959-966.

Dvorak HF, Orenstein NS, Carvalho AC, Churchill WH, Dvorak AM, Galli SJ, Feder J, Bitzer AM, Rypyse J \& Giovinco P 1979 Induction of a fibrin-gel investment: an early event in line 10 hepatocarcinoma growth mediated by tumor-secreted products. Journal of Immunology 122 166-174.
Fava RA, Olsen NJ, Spencer-Green G, Yeo K-T, Yeo T-K. Berse B, Jackman RW, Senger DR, Dvorak HF \& Brown LF 1994 Vascular permeability factor/endothelial growth factor (VPF/VEGF): accumulation and expression in human synovial fluids and rheumatoid synovial tissue. Journal of Experimental Medicine $\mathbf{1 8 0}$ 341-346.

Ffrench-Constant C, Van De Water L, Dvorak HF \& Hynes RO 1989 Reappearance of an embryonic pattern of fibronectin splicing during wound healing in the adult rat. Journal of Cell Biology 109 903-914.

Gitay-Goren H, Cohen T, Tessler S, Soker S, Gengrinovitch S, Rockwell P, Klagsbrun M, Levi B-Z \& Neufeld G 1996 Selective binding of $\mathrm{VEGF}_{121}$ to one of the three vascular endothelial growth factor receptors of vascular endothelial cells. Journal of Biological Chemistry 271 5519-5523.

Harper MJK 1988 Gamete and zygote. In The Physiology of Reproduction, pp 103-134. Eds E Knobil \& J Neil. New York: Raven Press.

Houck KA, Ferrara N, Winer J, Cachianes G, Li B \& Leung DW 1991 The vascular growth factor family: identification of a fourth molecular species and characterization of alternating splicing of RNA. Molecular Endocrinology 5 1806-1814.

Houck KA, Leung DW, Rowland AM, Winer J \& Ferrara N 1992 Dual regulation of vascular endothelial growth factor bioavailability by genetic and proteolytic mechanisms. Journal of Biological Chemistry 267 26031-26037.

Hyder SM, Stancel GM, Chiappetta C, Murthy L, Boettger-Tong HL \& Makela S 1996 Uterine expression of vascular endothelial growth factor is increased by estradiol and tamoxifen. Cancer Research $\mathbf{5 6}$ 3954-3960.

Joukov V, Sorsa T, Kumar V, Jeltsch M, Claesson-Welsch L, Cao Y, Saksela O, Kalkkinen N \& Alitalo K 1997 Proteolytic processing regulates receptor specificity and activity of VEGF-C. EMBO Journal 16 3898-3911.

Kamat BR, Brown LF, Manseau EJ, Senger DR \& Dvorak HF 1995 Expression of vascular permeability factor/vascular endothelial growth factor by human granulosa and theca lutein cells. Role in corpus luteum development. American Journal of Pathology 146 157-165.

Koch AE, Harlow LA, Haines GK, Amento EP, Unemori EN, Wong WL, Pope RM \& Ferrara N 1994 Vascular endothelial growth factor: A cytokine modulating endothelial function in rheumatoid arthritis. Journal of Immunology 152 4149-4156.

Koos RD \& Olson CE 1991 Hypoxia stimulates expression of the gene for vascular endothelial growth factor (VEGF), a putative angiogenic factor, by granulosa cells of the ovarian follicle, a site of angiogenesis. Journal of Cell Biology 115 421A.

Kumar MSA \& Chen CL 1983 Effect of an acute dose of delta delta 9-THC on hypothalamic luteinizing hormone releasing hormone, met-enkephalin content and serum levels of testosterone and corticosterone in rats. Substance and Alcohol Actions/Misuse 4 37-43.

Kumar MSA \& Simpkins JW 1983 Naloxone blocks the effects of delta 9-tetrahydrocannabinol on serum luteinizing hormone and prolactin in rats. Substance and Alcohol Actions/Misuse 4 347-353.

Leung DW, Cachianes G, Kuang W-J, Goeddel DV \& Ferrara N 1989 Vascular endothelial growth factor is secreted angiogenic mitogen. Science 246 1306-1309.

Marchand JE, Zaccheo TS, Connelly CS \& Kream RM 1993 Selective in situ hybridization histochemical analyses of alternatively spliced mRNAs encoding beta- and gamma-preprotachykinins in rat central nervous system. Brain Research. Molecular Brain Research 17 83-94.

Millauer B, Wizigmann-Voos S, Schnurch H, Martinez R, Moller NPH, Risau W \& Ullrich A 1993 High affinity VEGF binding and developmental expression suggest Flk-1 as a major regulator of vasculogenesis and angiogenesis. Cell 72 835-846. 
Montesano R, Kumar S, Orci L \& Pepper MS 1996 Synergistic effect of hyaluronan oligosaccharides and vascular endothelial growth factor on angiogenesis in vitro. Laboratory Investigation 75 249-262.

Moscatelli D \& Rifkin DB 1988 Membrane and matrix localization of proteinases: a common theme in tumor invasion and angiogenesis. Biochimica et Biophysica Acta 948 67-85.

Mukhopadhyay D, Tsiokas L, Zhou X-M, Foster D, Brugge SS \& Sukhatme VP 1995 Hypoxic induction of human vascular endothelial factor expression through c-Src activation. Nature $\mathbf{3 7 5}$ 577-581.

Phillips HS, Hains J, Leung DW \& Ferrara N 1990 Vascular endothelial growth factor is expressed in rat corpus luteum. Endocrinology 127 965-967.

Plate KH, Breier G, Weich HA \& Risau W 1992 Vascular endothelial growth factor is a potential angiogenesis factor in human gliomas in vivo. Nature $359845-848$.

Quinn TP, Peters KG, De Vries C, Ferrara N \& Williams LT 1993 Fetal liver kinase 1 is a receptor for vascular endothelial growth factor and is selectively expressed in vascular endothelium. Proceedings of the National Academy of Sciences of the USA 90 7533-7537.

Senger DR, Galli SJ, Dvorak AM, Perruzzi CA, Harvey VS \& Dvorak HF 1983 Tumor cells secrete a vascular permeability factor that promotes accumulation of ascites fluid. Science 219 983-985.

Senger DR, Perruzzi CA, Feder J \& Dvorak HF 1986 A highly conserved vascular permeability factor secreted by a variety of human and rodent cell lines. Cancer Research 46 5629-5632.
Shibuya M, Yamaguchi S, Yamane A, Ikeda T, Tojo A, Matsushime H \& Sato M 1990 Nucleotide sequence and expression of a novel human receptor-type tyrosine kinase (flt) closely related to the fims family. Oncogene 5 519-524.

Shweiki D, Itin A, Soffer D \& Keshet E 1992 Vascular endothelial growth factor induced by hypoxia may mediate hypoxia-initiated angiogenesis. Nature 359 843-845.

Shweiki D, Itin A, Neufeld G, Gitay-Goren H \& Keshet E 1993 Patterns of expression of vascular endothelial growth factor (VEGF) and VEGF receptors in mice suggest a role in hormonally regulated angiogenesis. Journal of Clinical Investigation 91 2235-2243.

Tischer E, Mitchel R, Hartman T, Silva M, Gospodarowicz D, Fiddes JC \& Abraham JA 1991 The human gene for vascular endothelial growth factor. Multiple protein forms are encoded through alternative exon splicing. Journal of Biological Chemistry 266 11947-11954.

Vaisman N, Gospodarowicz D \& Neufeld G 1990 Characterization of the receptor for vascular endothelial growth factor. Journal of Biological Chemistry 265 19461-19466.

Weisz A \& Bresciani F 1988 Estrogen induces expression of c-fos and c-myc protooncogenes in rat uterus. Molecular Endocrinology 2 816-824.

Received 4 December 1997

Revised manuscript received 27 May 1998

Accepted 17 August 1998 